\title{
Onset of estrus and preovulatory LH surge and ovulatory efficiency in sheep after short-term treatments with progestagen-sponges and progesterone-CIDRs
}

\author{
P Martinez-Ros ${ }^{1}$, S Astiz ${ }^{2}$, E Garcia-Rosello ${ }^{3}$, A Rios-Abellan', A Gonzalez-Bulnes ${ }^{2,4}$ \\ ${ }^{1}$ Dpto. Produccion y Sanidad Animal, Facultad de Veterinaria, Universidad Cardenal \\ Herrera-CEU, CEU Universities, Valencia, Spain \\ ${ }^{2}$ Dpto. de Reproduccion Animal, INIA, Madrid, Spain \\ ${ }^{3}$ Dpto. Medicina y Cirugia Animal, Facultad de Veterinaria, Universidad Cardenal \\ Herrera-CEU, CEU Universities, Valencia, Spain \\ ${ }^{4}$ Dpto. de Toxicologia y Farmacologia, Facultad de Veterinaria, UCM Madrid, Spain.
}

Correspondence: Paula Martinez-Ros, Dpto. Produccion y Sanidad Animal, Facultad de Veterinaria, Universidad Cardenal Herrera-CEU, C/ Tirant lo Blanc, 7.46115 Alfara del Patriarca Valencia, Spain. E-mail: paula.martinez@uchceu.es

\section{Contents}

The present study supports that short-term (7-days) protocols based on progestagenimpregnated sponges and progesterone-loaded CIDRs are equally effective to induce ovulatory response in sheep. There were no significant differences in the onset of estrus behavior $(32.0 \pm 6.0$ and $33.8 \pm 4.0 \mathrm{~h}$ after device withdrawal for sponges and CIDRs, respectively; $p>.05)$ and preovulatory LH discharge $(5.1 \pm 2.1$ and $5.8 \pm 3.3 \mathrm{~h}$ after onset of estrus behavior for sponges and CIDRs, respectively; $p>.05)$. These features are similar to previously described for classical long-term (12-14 days) treatments. Hence, short-term CIDR-based protocols may be implemented using the same time-intervals for insemination than sponge-based and long-term protocols.

\section{INTRODUCTION}

In Europe, the protocols for induction and synchronization of estrus and ovulation in sheep are traditionally based on the insertion of progestagen-impregnated intravaginal sponges (Abecia et al., 2012). A different device has been authorized for commercialization in the European Union in the current year 2018, the CIDR $^{\circledR}$ (Controlled Internal Drug Releasing device, Pfizer Inc., USA), after being widely used in countries of America, Australia and New Zealand from its development in the 1980s (Knight \& Hall, 1988, Wheaton et al., 1993). The CIDR is a Y-shaped silicon-based device, loaded with progesterone instead of impregnated with progestagens. The design and composition allow the drainage of vaginal secretions and reduce the rates of device loss, adherence and vaginitis (Suarez et al., 2006) despite of the fact that treatments with progesterone or progestagens are equally related to induction of vaginitis (Vasconcelos et al., 2016). Previous studies have also addressed that the physical characteristics of the CIDR device allow them to be washed and reused without significant consequences on reproductive parameters (Pinna et al., 2012).

The reproductive outputs after using CIDR, in terms of fertility, are reported to be similar to progestagen-sponges (Hill et al., 1998, Ungerfeld \& Rubianes 2002, Ozyurtlu et al. 2010) or even higher (Swelum et al., 2015). However, some authors indicate a lower percentage of sheep developing estrus (Knight and Hall 1988) and an earlier and more disperse temporal distribution of estrus onset after CIDR than after sponge treatments (Smith, 1991, Fukui et al., 1993, Tondello Martins et al., 2010). These features, although not found by other authors (Hashemi et al., 2006; Ozyurtlu et al., 2010), may prejudice the yields obtained after fixed-term artificial insemination by varying timing of preovulatory LH surge and later ovulation and mismatching them with timing of insemination. 
Hence, we developed a comparative study on the onset of estrus behavior and preovulatory LH peak in sheep treated with either FGA-impregnated sponges or progestagen-loaded CIDRs in short-term protocols (seven days). Such data may give substantial information for adapting protocols of artificial insemination and reaching maximal fertility.

\section{MATERIAL AND METHODS}

The experiment was approved by the Universidad CEU-Cardenal Herrera Committee of Ethics in Animal Research (report CEEA17/019) and involved 49 ewes, 2-5 years-old and mean body-score of $3.8 \pm 0.3$, from the experimental farm of the University at Naquera (Valencia, Spain; latitude $39^{\circ} \mathrm{N}$ ).

Sheep were divided in two groups, which were treated during reproductive season (February). The first group (SPONGE; $\mathrm{n}=24$ ) was treated by the insertion of one intravaginal progestagen-impregnated sponge $(20 \mathrm{mg}$ fluorogestone acetate, FGA, Chronogest $^{\circledR}$, MSD Animal Health, Madrid, Spain) whilst the second group (CIDR; $n=25$ ) was treated with one intravaginal progesterone-loaded CIDR (CIDR ${ }^{\circledR}$ Ovis, Zoetis, Madrid, Spain). The devices were maintained for seven days and, at their removal, all the ewes in both groups received, i.m., $5 \mathrm{mg}$ of prostaglandin $\mathrm{F}_{2 \alpha}$ (Dinolytic ${ }^{\circledR}$, Zoetis, Madrid, Spain) and 400 IU of eCG (Foligon ${ }^{\circledR}$, MSD Animal Health, Madrid, Spain).

The variables evaluated were timing of onset of estrus behavior, timing of onset of the preovulatory LH surge and ovulation rate. Signs of estrus behavior were determined every $4 \mathrm{~h}$ from 12 to $60 \mathrm{~h}$ after device withdrawal. Interval from treatment to estrus onset was defined by the time elapsed between device removal and the first accepted mating. The characteristics of the preovulatory LH surge were evaluated by collecting jugular blood samples at $4 \mathrm{~h}$ intervals from 32 to $80 \mathrm{~h}$ after device withdrawal. Plasma LH was measured using a commercial enzimoimmunoassay kit (LH Detect ${ }^{\circledR}$, INRA, Tours, France), with sensitivity of $0.01 \mathrm{ng} / \mathrm{mL}$ and inter- and intra-assay variation coefficients of $7.4 \%$ and $8.5 \%$, respectively. Finally, the number of corpora lutea was determined by transrectal ultrasonography (Aloka SSD 500 with a $7.5 \mathrm{MHz}$ linear-array probe, Aloka Co. Ltd., Tokyo, Japan) at Day 11 of the induced estrous cycle.

Statistical analysis was performed using SPSS ${ }^{\circledR} 22.0$ (IBM Corporation, New York NY, USA). The response to treatments was analyzed using chi square test. All the results were expressed as mean \pm standard deviation and the statistical significance was accepted from $p<.05$.

\section{RESULTS}

The percentage of animals showing estrus behavior over time after intravaginal device withdrawal is depicted in Figure 1. All the sheep in both groups showed estrus behavior in response to the treatment, without significant differences in the timing of its onset after device withdrawal. Mean timing ( \pm standard deviation) was $32.0 \pm 6.0 \mathrm{~h}$ for the group SPONGE (range: $16-40 \mathrm{~h}$ ) and $33.8 \pm 4.0 \mathrm{~h}$ for the group CIDR (range: $24-40 \mathrm{~h}$ ).

Afterwards, all the ewes showing estrus behavior also showed a preovulatory LH surge. The percentage of animals showing a preovulatory LH peak over time after estrus behavior is depicted in Figure 2. There were, like for timing of estrus appearance, no significant differences between groups in the mean timing for the onset of the preovulatory LH peak, which were $5.1 \pm 2.1 \mathrm{~h}$ for the group SPONGE (range: $4-12 \mathrm{~h}$ ) and $5.8 \pm 3.3 \mathrm{~h}$ for the group CIDR (range: 4-16h). Concomitantly, there were no differences in mean plasma LH concentrations at the preovulatory surge $(32.7 \pm 3.1 \mathrm{ng} / \mathrm{mL}$ for the group SPONGE and $35.5 \pm 3.8 \mathrm{ng} / \mathrm{mL}$ for the group CIDR). 
All the ewes showing estrus behavior ovulated regardless of the treatment, without significant differences between treatments in the number of corpora lutea $(2.2 \pm 1.0$ for SPONGE and $2.0 \pm 1.0$ for CIDR).

\section{DISCUSSION}

The present study supports that short-term protocols with FGA-impregnated sponges and progestagen-loaded CIDRs are equally effective for inducing estrus behavior, preovulatory LH discharge and ovulation in sheep. All the animals in both groups responded to the treatments displaying estrus behavior and ovulation, without significant differences in the mean timing and temporal distribution of the onset of estrus behavior and preovulatory LH discharge in agreement with previous reports (Hashemi et al., 2006; Ozyurtlu et al., 2010). Hence, our results support that CIDR-based protocols should be designed using the same time-intervals for insemination than sponge-based protocols.

The current work used a short-term protocol (7 days) instead of a classical long-term treatment (12-14 days), so the results are also useful to support the suitability of short-term progestagen treatment for managing reproduction in sheep (Menchaca \& Rubianes, 2004; dos Santos-Neto et al., 2015). Mean timing and distribution of estrus behavior after 7 days of treatment, in both sponge- and CIDR-groups, were similar to previous studies based on 12 days (Hashemi et al., 2006; Ozyurtlu et al., 2010). Hence, these results also support that the use of short-term protocols, either using sponges or CIDRs, may be based in similar intervals for insemination than long-term protocols but obviously considering possible influences by factors like season of the year or semen type.

\section{ACKNOWLEDGMENTS}

The authors thank the CEU-Cardenal Herrera farm staff for their assistance with animal care and handling.

\section{CONFLICT OF INTEREST}

All authors declare no competing interests for publication in this Journal.

\section{AUTHOR CONTRIBUTIONS}

PMR, designing and performing the study and writing the article; SAB, designing the study and performing the statistical analysis and final revision of the article; EGR, collection of animal data and final revision of the article; ARA, collection of animal data and final revision of the article; AGB, designing the study and writing the article.

\section{REFERENCES}

Abecia, J.A., Forcada, F., \& Gonzalez-Bulnes, A. (2012). Hormonal control of reproduction in small ruminants. Animal Reproduction Science 130,173-179.

dos Santos-Neto, P.C., García-Pintos, C., Pinczak, A., \& Menchaca, A. (2015). Fertility obtained with different progestogen intravaginal devices using short-term protocol for fixed-time artificial insemination (FTAI) in sheep. Livestock Science, 182, 125-128.

Fukui, Y., Hirai, H., Honda, K., \& Hayashi, K. (1993). Lambing ratesby fixed-timed intrauterine insemination with frozen semenin seasonally anoestrous ewes treated with a progestagen-impregnated sponge or CIDR device. Journal of Reproduction and Development, 39, 1-5.

Hashemi, M., Safdarian, M., \& Kafi, M. (2006). Estrus response to synchronization of estrus using different progesterone treatments outside the natural breeding season in ewes. Small Ruminant Research, 65, 279-283. 
Hill, J.R., Thompson, J.A., \& Perkins, N.R. (1998). Factors affecting pregnancy rates following laparoscopic insemination of 28,447 Merino ewes under commercial conditions: a survey. Theriogenology, 49, 697-709.

Knight, T.W., \& Hall, D.R.H. (1988). Effect of immunisation withpolyandroalbumin (Fecundin); pasture allowance, post-mating shearing and method of synchronisation on reproductive performance of Romney and Marshall Romney ewes. New Zealand Journal of Agricultural Research, 31, 243-247

Menchaca, A., \& Rubianes, E. (2004). New treatments associated with timed artificial insemination in small ruminants. Reproduction Fertility and Development, 16, 403-414.

Ozyurtlu, N., Kucukaslan, I., \& Cetin, Y. (2010). Characterization of oestrous induction response, oestrous duration, fecundity and fertility in Awassi ewes during the nonbreeding season utilizing both CIDR and intravaginal sponge treatments. Reproduction in Domestic Animals, 45, 464-467.

Pinna, A.E., Brandão, F.Z., Cavalcanti, A.S., Borges, A.M., Souza, J.M.G., \& Fonseca, J.F. (2012). Reproductive parameters of Santa Inês ewes submitted to short-term treatment with re-used progesterone devices. Arquivo Brasileiro de Medicina Veterinária e Zootecnia, 64, 333-340.

Smith, J.F., Konlechner, J.A., \& Parr, J. (1991). Factors influencing the time to onset of oestrus after synchronisation treatment in ewes. Proceedings of the New Zealand Society of Animal Production, 51, 117-121.

Suarez, G., Zunino, P., Carol, H., \&Ungerfeld R. (2006). Changes in the aerobic vaginal bacterial mucous load and assessment of the susceptibility to antibiotics after treatment with intravaginal sponges in anestrous ewes Small Ruminant Research, 63, 39-43.

Swelum, A.A., Alowaimer, A.N., \& Abouheif, M.A. (2015) Use of fluorogestone acetate sponges or controlled internal drug release for estrus synchronization in ewes: Effects of hormonal profiles and reproductive performance. Theriogenology, 84, 498-503.

Tondello Martins, L., Santos Neto, P.C., Gaudêncio Neto, S., Pereira Rauber, L., Bertolini, M., Diniz Vieira, A., \& Mezzalira, A. (2010) Microbiological and functional evaluation of an alternative device $(\mathrm{OB} \otimes)$ for estrous synchronization in ewes. Ciência Rural, 40, 389-395.

Ungerfeld, R., \& Rubianes, E. (2002). Short term priming with different progestogen intravaginal devices (MAP, FGA and CIDR) for eCG-estrous induction in anestrous ewes. Small Ruminants Research, 46, 63-66.

Vasconcelos, C., Brandão, F.Z., Martins, G., Penna, B., Souza J.M.G., \& Lilenbaum W. (2016) Qualitative and quantitative analysis of bacteria from vaginitis associated with intravaginal implants in ewes following estrus synchronization. Ciência Rural, Santa Maria, 46, 632-636.

Wheaton, J.E., Carlson, K.M., Windels, H.F., \& Johnston, L.J. (1993). CIDR - a new progesterone-releasing intravaginal device for induction of estrus and cycle control in sheep and goats. Animal Reproduction Science, 33, 127-141. 

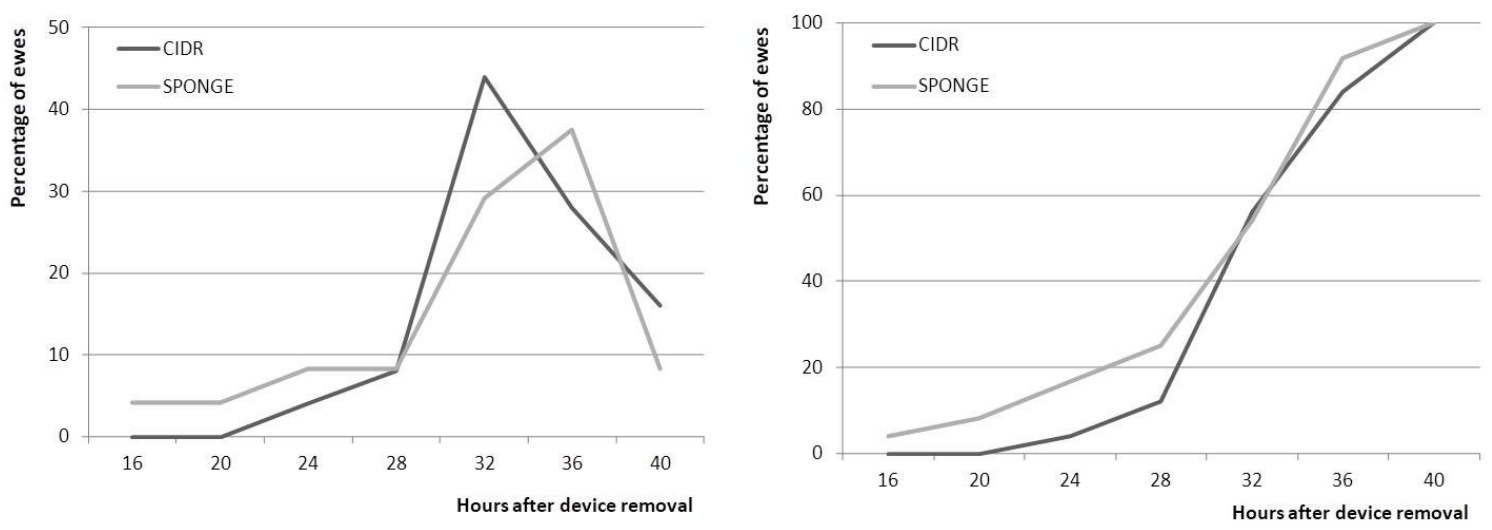

Figure 1. Absolute (left panel) and cumulative percentage of ewes (right panel) showing estrus behavior over time after intravaginal device withdrawal in sheep treated with either progestagen-impregnated sponges or progesterone-loaded CIDRs. 

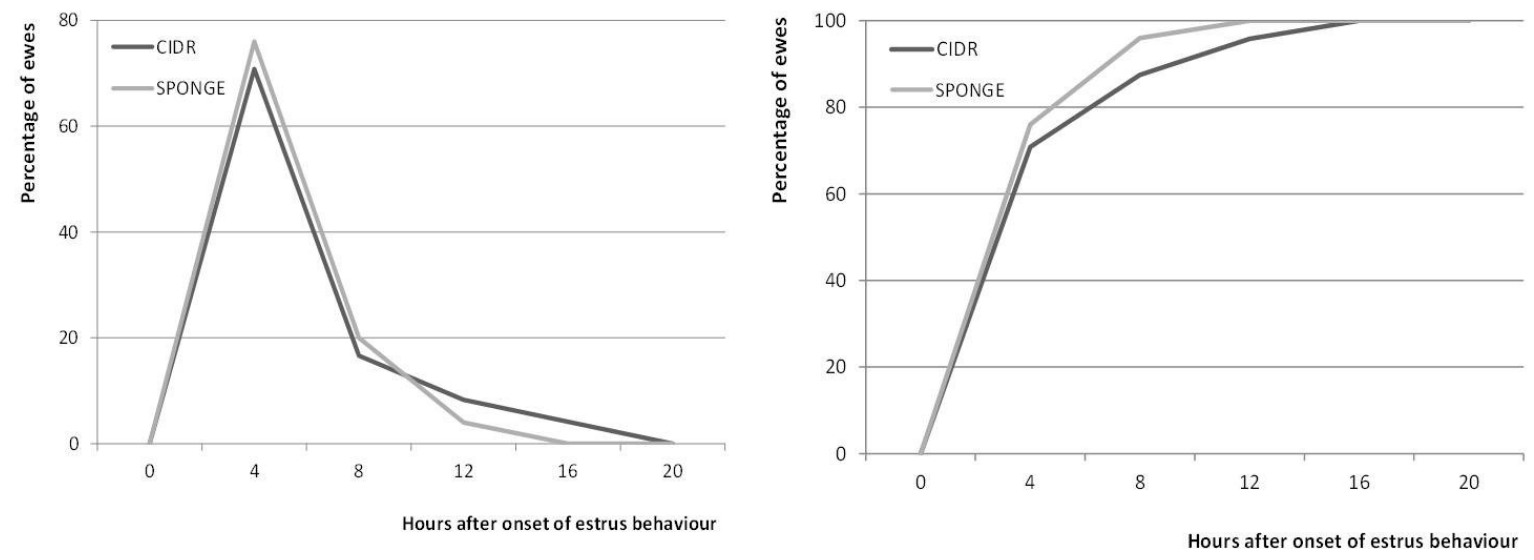

Figure 2. Absolute (left panel) and cumulative percentage of ewes (right panel showing preovulatory LH discharge over time after onset of estrus behavior in sheep treated with either progestagen-impregnated sponges or progesterone-loaded CIDRs. 